\title{
Impact of postoperative complications on long-term survival following surgery for T4 colorectal cancer
}

\author{
Michael Osseis ${ }^{1} \mathbb{D}$, Francesco Esposito ${ }^{1}$, Chetana Lim¹, Alexandre Doussot ${ }^{1}$, Eylon Lahat ${ }^{1}$, Liliana Fuentes ${ }^{1}$, \\ Toufic Moussallem ${ }^{1}$, Chady Salloum ${ }^{1}$ and Daniel Azoulay ${ }^{1,2^{*}}$
}

\begin{abstract}
Background: Postoperative complications (POCs) after the resection of locally advanced colorectal cancer (CRC) may influence adjuvant treatment timing, outcomes, and survival. This study aimed to evaluate the impact of POCs on long-term outcomes in patients surgically treated for T4 CRC.

Methods: All consecutive patients who underwent the resection of T4 CRC at a single centre from 2004 to 2013 were retrospectively analysed from a prospectively maintained database. POCs were assessed using the ClavienDindo classification. Patients who developed POCs were compared with those who did not in terms of recurrencefree survival (RFS) and overall survival (OS).

Results: The study population comprised 106 patients, including 79 (74.5\%) with synchronous distant metastases. Overall, 46 patients (43\%) developed at least one POC during the hospital stay, and of those patients, 9 (20\%) had severe complications (Clavien-Dindo $\geq$ grade III). POCs were not associated with OS (65\% with POCs vs. 69\% without POCs; $p=0.72$ ) or RFS ( $58 \%$ with POCs vs. $70 \%$ without POCs; $p=0.37$ ). Similarly, POCs did not affect OS or RFS in patients who had synchronous metastases at diagnosis compared with those who did not.

Conclusions: POCs do not affect the oncological course of patients subjected to the resection of T4 CRC, even in cases of synchronous metastases.
\end{abstract}

Keywords: Postoperative complications, Colorectal, Survival, Recurrence, T4 tumors

\section{Background}

Colorectal cancer (CRC) is the third most common cancer type and the fourth cause of cancer-related deaths worldwide [1]. Nearly $10 \%$ to $20 \%$ of patients with CRC present with locally advanced disease, including peritoneal involvement (T4a) or invasion in adjacent organs (T4b) at diagnosis [2].

Long-term survival has improved in selected patients with clinically $\mathrm{T} 4$ colorectal cancer managed with the multimodal treatment strategy including surgery and perioperative chemotherapy. Patient selection remains of utmost importance as CRC resection for $\mathrm{T} 4$ lesions is

\footnotetext{
* Correspondence: daniel.azoulay@hmn.aphp.fr

${ }^{1}$ Department of Digestive, Hepatobiliary and Pancreatic Surgery and Liver Transplantation, Henri Mondor Hospital, APHP, UPEC, 51 avenue de Lattre de Tassigny, 94010 Créteil, France

2INSERM, U955, Créteil, France
}

associated with significant morbidity rate ranging from 30 to $40 \%[3,4]$.

Postoperative complications are associated with increased hospital stay and in-hospital costs $[5,6]$. There is increasing evidence reporting that the postoperative complications were also risk factors for the survival or tumor recurrence in various types of abdominal malignancies including esophageal, gastric, and liver cancers [7-10]. In CRC patients, reports that have studied the effect of postoperative morbidity following resection on long-term survival have yielded conflicting results. To our knowledge, the effect of postoperative morbidity following surgery of T4 CRC has never been reported. Despite several studies performed in CRC patients, most studies have many limitations including heterogeneous disease stages populations, with a relatively small sample size of T4 CRC patients (Table 1). 


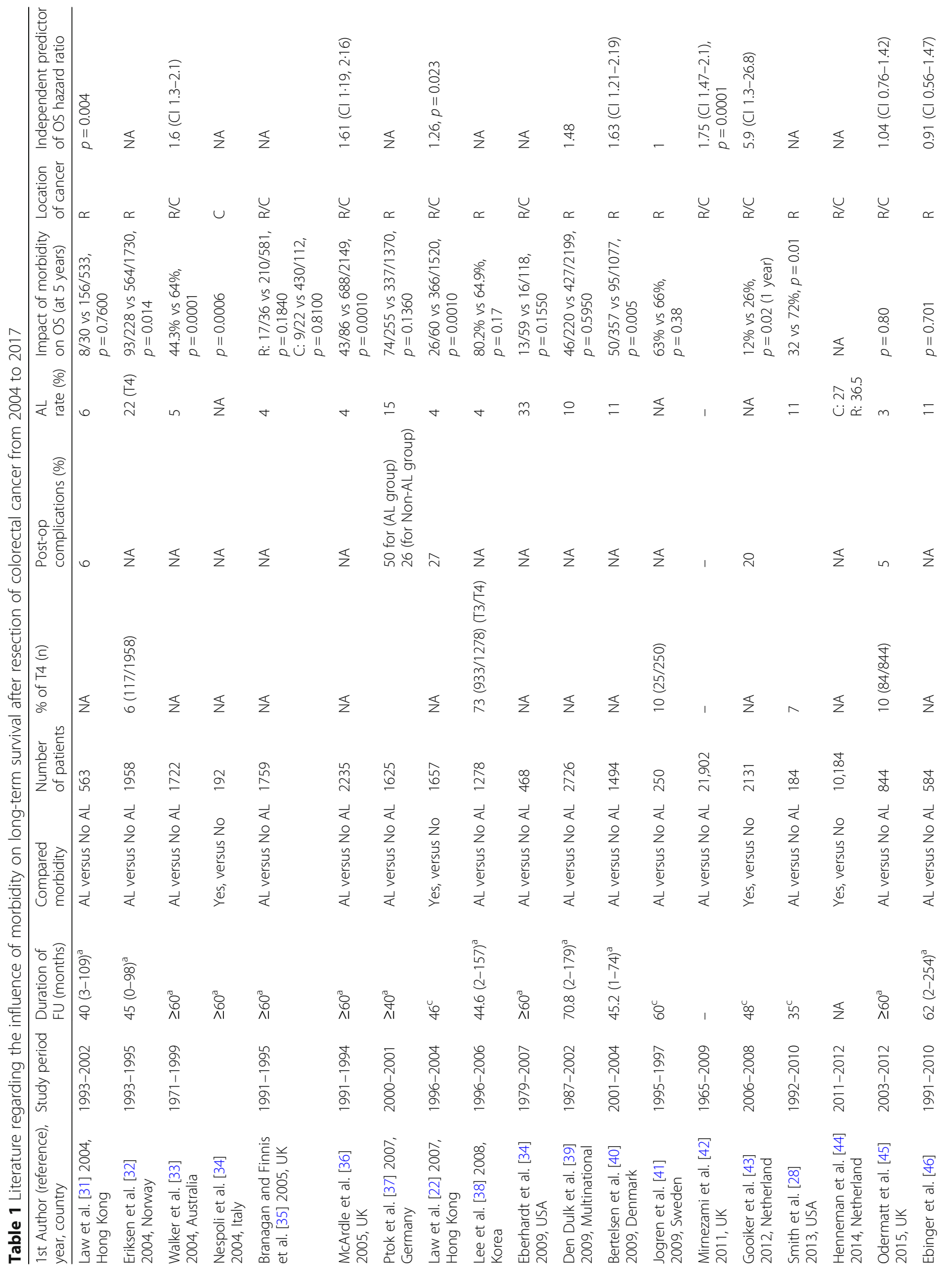


Osseis et al. BMC Surgery (2018) 18:87

Page 3 of 11

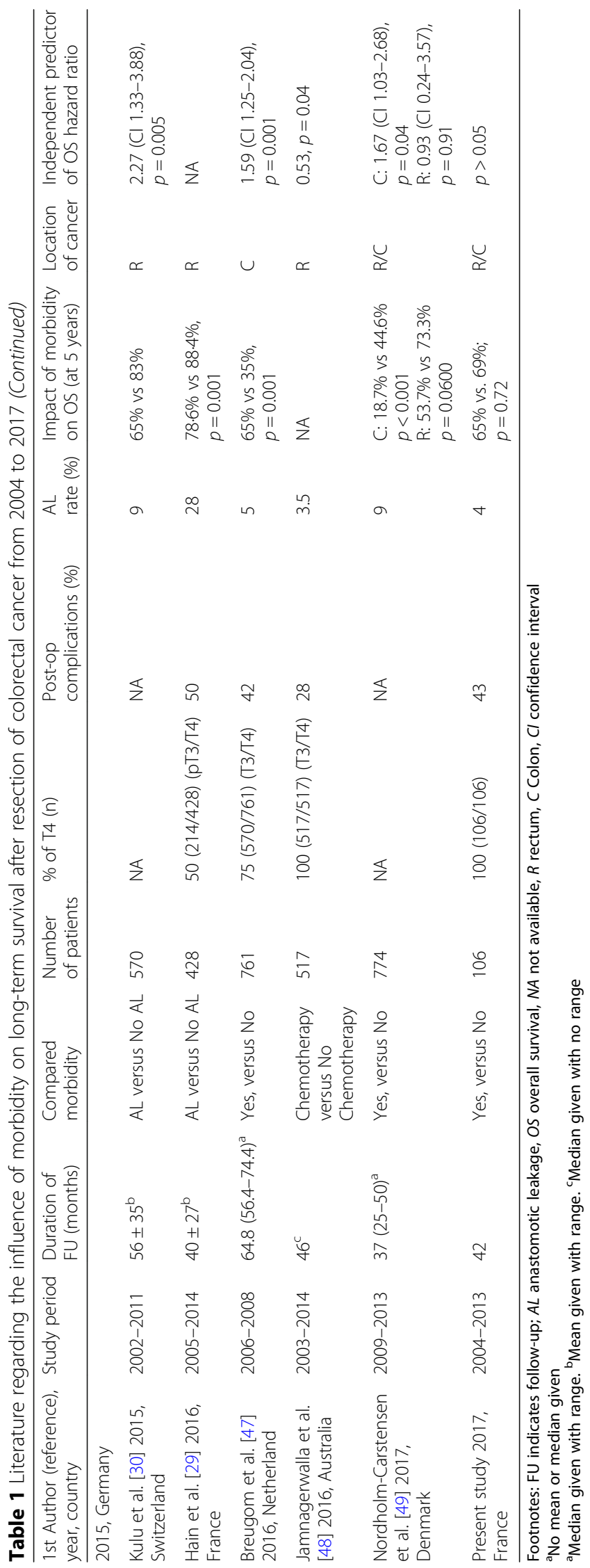


The above knowledge was the impetus for the present study which aimed to evaluate the impact of postoperative morbidity on long-term outcomes following potentially curative resection for colorectal cancer.

\section{Methods \\ Patients}

All consecutive patients who underwent either elective or urgent surgery with histologically proven T4 CRC on final resected specimens were retrospectively identified from a prospectively maintained database of patients undergoing laparoscopic or open colorectal resection at Henri Mondor Hospital between January 2004 and December 2013. Patients were categorized into two groups: with synchronous distant metastases (stage IV according to the American Joint Committee on Cancer) or without (stage II-III). Patients who died within 90 days of surgery were not considered for inclusion in this study because they were not exposed to recurrence.

\section{Perioperative management and surgical techniques}

All patients underwent a preoperative evaluation, including colonoscopy with tumour biopsy and thoraco-abdominopelvic computed tomography (CT) scan. In cases of rectal cancer, pelvic magnetic resonance imaging (MRI) and endorectal ultrasonography were performed for local rectal cancer staging. Liver MRI was systematically performed in case of synchronous liver metastases diagnosed by CT.

In patients with mid or low rectal cancer who underwent elective surgery, the indications were for neoadjuvant long-course chemoradiation therapy (45-50.4 Gy delivered in daily fractions of 1.8-2 Gy over a 5- to 6-week period combined with 5-fluorouracil [5-FU] or capecitabine [Xeloda]). Short-course radiotherapy $(5 \times 5$ Gy for 1 week) or chemotherapy alone were determined by multidisciplinary cancer boards according to local standards. Surgery was performed 6 to 8 weeks after the completion of chemo-radiotherapy and immediately after short-course radiotherapy.

All patients were operated with a curative intent. During the study period, the following oncological principles were applied: vascular control at the root of the corresponding mesenteric axis for appropriate lymphadenectomy and multivisceral en bloc resection in cases of adhesion to adjacent organs. Total mesorectal excision was performed in cases of mid or low rectal cancer [11]. Curative resection was defined as the complete removal of all macroscopically evident disease at the time of surgery and tumour-free resection margins on histological examination. A diverting ileostomy was performed in all cases of infraperitoneal colorectal anastomosis.

\section{Definitions and study design}

Any postoperative event occurring within 90 days and deemed as leading to any deviation from the normal postoperative course was considered a complication [12]. Surgical complications included anastomotic leakage, bleeding, ileus, intraabdominal or pelvic abscess, and wound infection. Anastomotic leakage was defined and given one of three grades (A, B and C) according to the international study group of rectal cancer [13]. Non-surgical complications included renal, pulmonary, cardiac, and infectious complications. Postoperative complications (POCs) were graded according to the Clavien-Dindo staging system [14]. Grade III and IV complications were considered as severe complications.

All patients participated in an oncological follow-up program every 3 months for the first 2 years and every 6 months thereafter. Abdominal and chest CT scans with a blood test including carcinoembryonic antigen levels were routinely performed during every follow-up visit. A full colonoscopy was performed 1 to 2 years after surgery and then once every 4 years. If recurrence was suspected, MRI and/or positron emission tomography$\mathrm{CT}$ were used to confirm the diagnosis. Biopsies were selectively performed.

Patients were divided in two groups: patients who did and did not develop POCs. The two groups were then compared in terms of OS and recurrence-free survival (RFS). Additionally, the time from surgery to adjuvant chemotherapy was retrieved to measure the impact of POCs on adjuvant chemotherapy delivery.

This study was approved by the local institutional review board and ethics committee of Henri Mondor Hospital, conformed to the ethical guidelines of the 1975 Declaration of Helsinki.

\section{Statistical analysis}

Continuous variables are presented as the mean (SD); all other variables are presented as the median (range) and were compared using the Mann-Whitney $U$ test. RFS and OS were estimated using the Kaplan-Meier method. Survival differences between groups were compared using the log-rank test. Variables that reached statistical significance $(p<0.05)$ in univariate analyses were included in a Cox proportional hazard model to identify independent prognostic predictors of OS and RFS. All analyses were performed using SPSS $^{\bullet}$ version 22.0 (IBM, Armonk, New York, USA).

\section{Results}

\section{Study population}

According to the objective of the study, 17 patients were excluded from the analysis-8 (6.5\%) died within 90 days of surgery, and 9 were lost to follow-up. The remaining 106 patients represented the study population (Table 2). 
Table 2 Demographics, perioperative variables, and histopathological findings

\begin{tabular}{|c|c|c|c|c|}
\hline Variable & $\begin{array}{l}\text { Total } \\
n=106\end{array}$ & $\begin{array}{l}\text { No complication } \\
n=60 \\
(56 \%)\end{array}$ & $\begin{array}{l}\text { Any complication } \\
n=46 \\
(44 \%)\end{array}$ & $P$ \\
\hline Age (years) & $69 \pm 14$ & $70 \pm 14$ & $67 \pm 14$ & 0.27 \\
\hline Male sex & $46(43 \%)$ & $25(42 \%)$ & $21(46 \%)$ & 0.68 \\
\hline ASA score $>2$ & $13(12 \%)$ & $8(61.5 \%)$ & $5(38.5 \%)$ & 0.70 \\
\hline $\mathrm{BMI}$ & $24 \pm 6$ & $24 \pm 6$ & $25 \pm 6$ & 0.32 \\
\hline \multicolumn{5}{|l|}{ Comorbidity } \\
\hline Cardiovascular & $45(42 \%)$ & $25(55.5 \%)$ & $20(44.5 \%)$ & 0.85 \\
\hline Pulmonary & $20(19 \%)$ & $6(30 \%)$ & $14(70 \%)$ & 0.01 \\
\hline Diabetes & 17 (16\%) & $11(65 \%)$ & $6(35 \%)$ & 0.46 \\
\hline \multicolumn{5}{|l|}{ Localization } \\
\hline Rectum & $14(13 \%)$ & $9(64 \%)$ & $5(36 \%)$ & 0.53 \\
\hline Colon & $92(86 \%)$ & $51(55 \%)$ & $41(45 \%)$ & \\
\hline Synchronous metastasis & $27(25 \%)$ & $15(55.5 \%)$ & $12(44.5 \%)$ & 0.90 \\
\hline Stage IVA (liver only) & $18(67 \%)$ & $9(50 \%)$ & $9(50 \%)$ & \\
\hline Stage IVA (lung only) & $4(15 \%)$ & $3(75 \%)$ & $1(25 \%)$ & \\
\hline Stage IVB & $5(19 \%)$ & $3(60 \%)$ & $2(40 \%)$ & \\
\hline Serum CEA $(\mu / L)$ & $54 \pm 116$ & $71 \pm 140$ & $37 \pm 82$ & 0.25 \\
\hline Neoadjuvant radiotherapy or chemotherapy & $16(15 \%)$ & $9(56 \%)$ & 7 (44\%) & 0.98 \\
\hline Operative setting & & & & 0.51 \\
\hline Elective & $84(79 \%)$ & $48(57 \%)$ & $36(43 \%)$ & \\
\hline Emergent & $22(21 \%)$ & $12(54.5 \%)$ & $10(45.5 \%)$ & \\
\hline Surgical procedure & & & & 0.85 \\
\hline Abdominoperineal resection & $2(1.8 \%)$ & $1(50 \%)$ & $1(50 \%)$ & \\
\hline Hartmann's procedure & $7(6.6 \%)$ & $3(43 \%)$ & $4(57 \%)$ & \\
\hline Anterior resection & $17(16 \%)$ & $11(65 \%)$ & $6(35 \%)$ & \\
\hline Segmental resection & $80(75.5 \%)$ & $45(56 \%)$ & $35(44 \%)$ & \\
\hline Surgical approach & & & & 0.75 \\
\hline Open & $78(74 \%)$ & $43(55 \%)$ & $35(45 \%)$ & \\
\hline Laparoscopic & $28(26 \%)$ & $11(39 \%)$ & $17(61 \%)$ & \\
\hline Associated resection & $40(37.8 \%)$ & $23(57.5 \%)$ & $17(42.5 \%)$ & \\
\hline 1 organ & $23(49 \%)$ & $15(65 \%)$ & $8(35 \%)$ & 0.51 \\
\hline$>1$ organ & 17 (51\%) & $8(47 \%)$ & $9(53 \%)$ & \\
\hline Synchronous liver resection & $11(10.3 \%)$ & $5(45 \%)$ & $6(55 \%)$ & 0.88 \\
\hline Stoma & $42(39.6 \%)$ & $21(50 \%)$ & $21(50 \%)$ & 0.27 \\
\hline $\begin{array}{l}\text { Specimen analysis } \\
\mathrm{N}+\end{array}$ & $60(56.6 \%)$ & $35(58 \%)$ & $25(42 \%)$ & 0.68 \\
\hline Surgical margins status & & & & 0.35 \\
\hline RO & $85(80 \%)$ & $35(41 \%)$ & $50(59 \%)$ & \\
\hline R1 & $21(20 \%)$ & $11(52 \%)$ & $10(48 \%)$ & \\
\hline Adjuvant chemotherapy & 65 (61\%) & $32(53 \%)$ & $33(72 \%)$ & 0.06 \\
\hline Delay from surgery to chemotherapy (days) & $52 \pm 50$ & $55 \pm 62$ & $49 \pm 33$ & 0.69 \\
\hline
\end{tabular}

Footnotes: ASA American Society of Anaesthesiologists, BMI body mass index, CEA carcinoembryonic antigen 
The tumour was rectal in 15 patients (14\%) and colonic in 92 patients (86\%). One patient had combined colon and rectal cancer. Six patients (5.6\%) underwent preoperative and postoperative chemo-radiotherapy, and 10 patients (9\%) underwent preoperative chemotherapy alone. At presentation, 27 (26\%) patients had synchronous metastases: 18 (67\%) had stage IVA (liver only), 4 (15\%) had stage IVA (lung only), and 5 (19\%) had stage IVB CRC. Eighty-six patients (81\%) underwent elective CRC resection, and 20 (19\%) patients underwent emergent resection due to perforation or bleeding.

\section{Perioperative data and specimen analysis}

Intraoperative data are reported in Table 2. Surgery was performed by an open approach in 78 (74\%) patients and by a laparoscopic approach in 28 (26\%) patients. The surgical procedures included segmental colectomy in 80 patients (75\%), low anterior resection of the rectum in 17 patients (16\%), Hartmann's procedure in 7 patients (6.6\%), and abdominoperineal resection in 2 patients (1.9\%). Temporary faecal diversion was performed in 42 patients (40\%). In the latter subset of patients, the cancer was rectal in 13 cases, left colonic in 16 cases, right colonic in 9 cases, and transverse in 4 cases. Resection of adjacent organs was needed in 40 patients (38\%): one organ in 23 patients (22\%) and more than one organ in 17 patients (16\%). Concomitant hepatectomy for synchronous liver metastases was performed in 11 patients $(10 \%)$, and the en bloc resection of organs adjacent to the tumour was required in $29(27 \%)$ patients. The number and types of additional organs resection are reported in Additional file 1: Table S1.

Pathological findings included 21 R1 (20\%) and 85 R0 (80\%) CRC resections. The malignant infiltration of adherent organs was observed in 22 patients (21\%). Lymph nodes that tested positive for disease were found in 60 patients $(57 \%)$.

\section{Post-operative complications}

Pre- and perioperative variables associated with the development of POCs are presented in Table 2. Globally, the two groups did not differ in terms of demographics, clinical, and perioperative outcomes.

Forty-six patients developed POCs (morbidity rate $=$ $43 \%$ ), and the rate of severe complications (ClavienDindo grade $\geq 3$ ) was $8.5 \%$ ( 9 patients). Four patients (3.7\%) had anastomotic leakage-two were classified as grade A anastomotic leakage, and the other two were considered grade B. Details of complications are detailed in Table 3.

\section{Adjuvant therapy}

Sixty-five patients $(61 \%)$ received adjuvant chemotherapy after surgery. There was no significant difference in the delivery of adjuvant chemotherapy between the patient groups with and without POCs $(53 \%$ vs. $72 \%$, respectively; $p=0.06$ ). The delay from surgery to chemotherapy was not different between the two groups ( 55 vs. 49 days, respectively; $p=0.69$ ).

\section{Impact of POCs on long-term outcomes All stages combined}

The median follow-up was 42 [4-125] months. Overall, the 1-, 3- and 5-year OS rates were $91 \%, 79 \%$, and $67 \%$, respectively (Fig. 1). The 1-, 3- and 5-year RFS rates were $91 \%, 72 \%$, and $64 \%$, respectively (Fig. 2). In the multivariable analysis, no variables were identified as predictors of OS (data not shown), while the presence of positive lymph nodes was the sole independent predictor of decreased RFS rate (Table 4). POCs did not impact either OS or RFS in the entire cohort.

\section{Stage I-III disease}

In patients without synchronous metastases, the 1-, 3and 5-year OS rates did not differ between the two groups $(94 \%, 80 \%$, and $75 \%$, respectively, in the POCs group vs. $91.4 \%, 82 \%$, and $74.6 \%$, respectively, in the no POCs group; $p=0.77$ ). In the multivariable analyses, no variables were identified as predictors of OS; however, three variables were identified as independent predictors of low RFS rates: ASA score $>2$, positive lymph nodes, and R1 margins (Table 5). POCs did not impact either OS or RFS in patients who did not have synchronous metastases.

\section{Stage IV disease}

In patients with synchronous metastases, the 1-, 3- and 5 -year OS rates did not differ between the two groups (90\%, 65.6\%, and $21.9 \%$, respectively, in the POCs group vs. $85.7 \%, 77.9 \%$, and $59.4 \%$, respectively, in the no POCs group; $p=0.35$ ).

\section{Discussion}

To our knowledge, this is the first study to evaluate the effect of POCs on long-term outcomes following resection of T4 CRC. In this present single centre analysis of a homogeneous group of consecutive T4 CRC patients, OS and RFS rates were not significantly different between patients who developed POCs and those who did not. These results were maintained after patients' stratification for the presence of synchronous metastases.

In the present study, the overall morbidity rate was $43 \%$. This is consistent with the values reported in recent reports (POCs in the range of 33-45\%) [4, 15].

The laparoscopic approach was used in a relatively low proportion of patients in our study (26\%). Although the impact of this approach on postoperative morbidity and survival was beyond the scope of this study, the 
Table 3 Details of postoperative complications among 106 patients

\begin{tabular}{ll}
\hline & No. of patients (\%) \\
\hline Anastomotic leakage & $4(3.7 \%)$ \\
Infectious complications & \\
Pelvic abscess & $6(5.6 \%)$ \\
Intra-abdominal abscess & $6(5.6 \%)$ \\
Urinary infection & $4(3.7 \%)$ \\
Wound infection & $10(9.4 \%)$ \\
Non-infectious complications & \\
Ileus & $6(5.6 \%)$ \\
Kidney failure & $2(1.8 \%)$ \\
Pulmonary failure/pleuresia & $4(3.7 \%)$ \\
Intra-abdominal bleeding & $1(0.9 \%)$ \\
Cardiac problems & $2(1.8 \%)$ \\
\hline Accordng
\end{tabular}

According to Clavien-Dindo classification

Patients may have had more than one complication

laparoscopic approach might contribute to contain the postoperative morbidity (POCs in the range of 7-26\%) [16-18] and to improve the oncologic results [16]. These results were further confirmed by two recent studies using propensity score methodology $[19,20]$. However, the rate of conversion rate remains relatively high, varying between 8 and 28\% [16-18, 21]. Further studies are needed to ascertain the real impact, if any, of laparoscopic approach on the incidence of postoperative morbidity in the specific setting of T4 CRC.
In this study, POCs did not impact on OS. The impact of POCs on the long-term prognosis of patients following different surgeries has recently been investigated. Khuri et al. used data from the National Surgical Quality Improvement Program to study the effects of POCs on the survival rate of more than 100,000 patients who underwent eight major operations [7]. In contrast with our results, the study showed that the occurrence of POCs within the first 30 days, independent of the patient's preoperative risk, reduced the median survival by $69 \%$. This latter study also showed that in patients who underwent a colectomy, there was a significant difference of $14.5 \%$ in mortality at 5 years between those who did and did not have complications. However, it is important to note that the group of patients who underwent colectomies in this study (13,310/100,000 patients) is a heterogeneous group with different indications for colectomy, not only for colon cancer. The present study included only patients who underwent surgical treatment for locally advanced CRC, which might explain this discrepancy between the results of the 2 studies. In a recent study by Law et al. [22], the occurrence of POCs was an independent factor associated with a worse overall survival and a higher overall recurrence rate. However, the impact of POCs on the survival and oncologic outcome in patients with T4 CRC was not clarified.

Whereas positive lymph node status was identified as the sole independent predictor of a decreased RFS, POCs did not impact on DFS even after patients' stratification for the presence of synchronous distant metastases. These
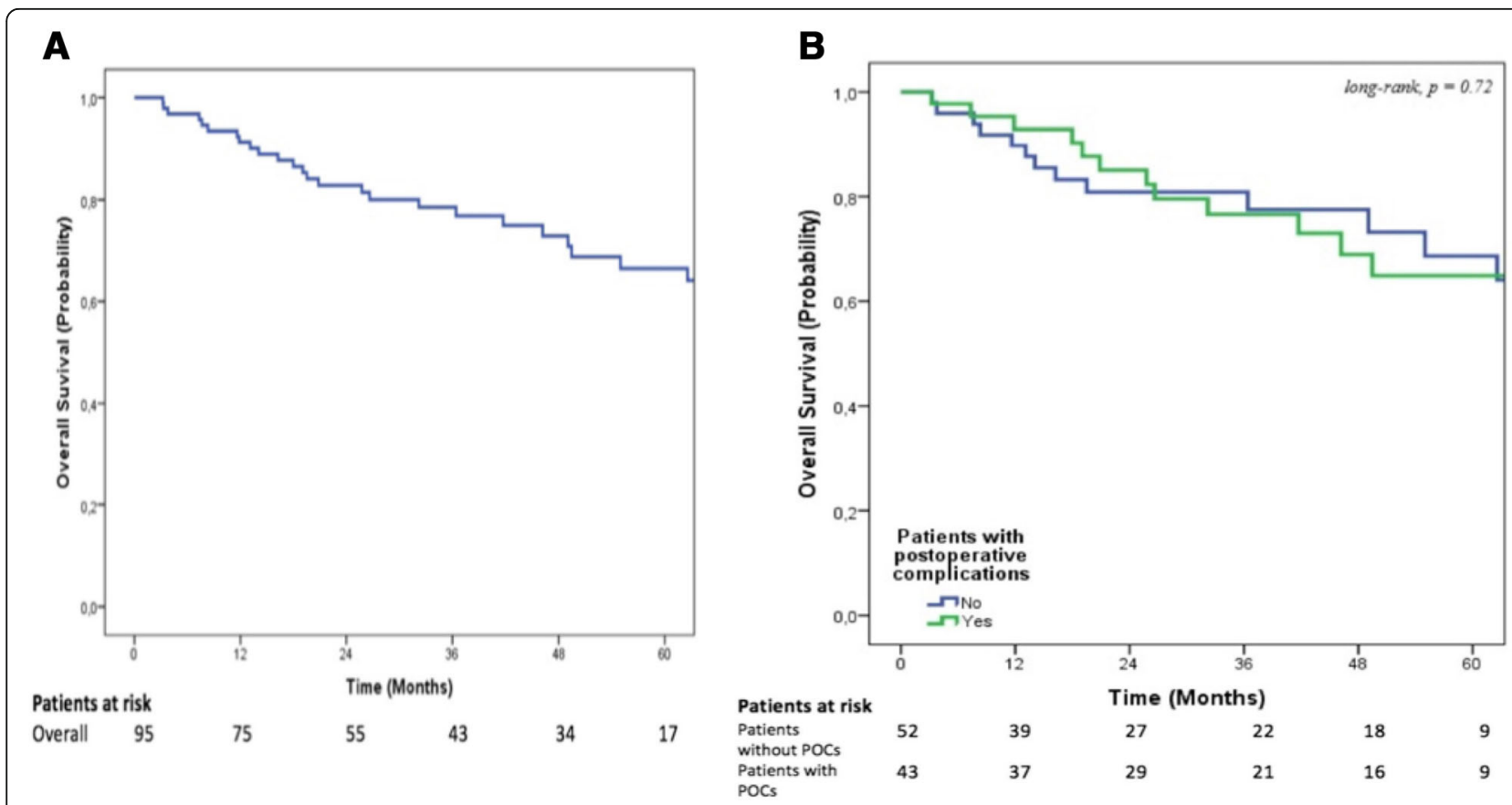

Fig. 1 Overall survival. a In the entire cohort. b Stratified according to the presence of postoperative complications 


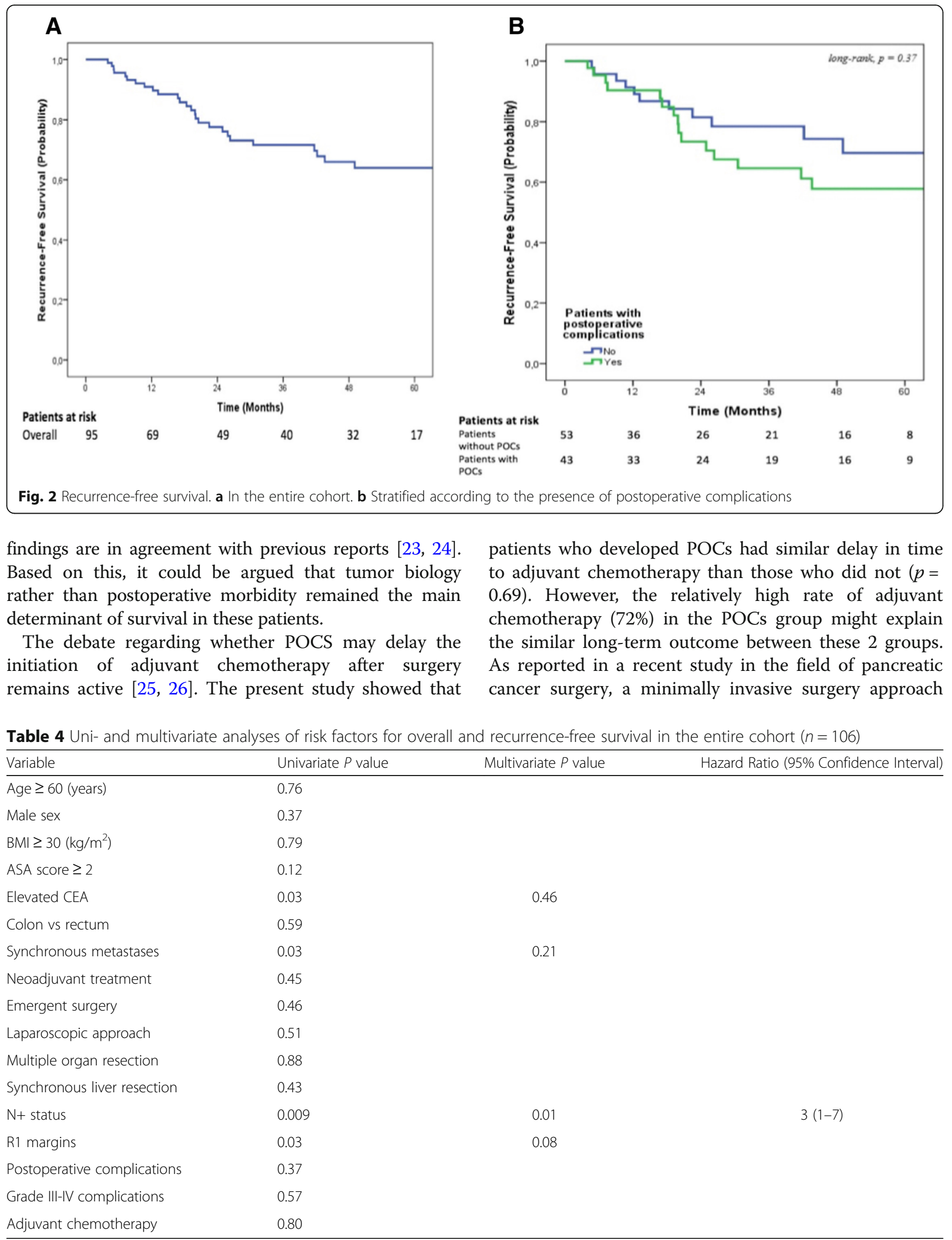

Footnotes: $B M I$ indicates body mass index, ASA American Society of Anesthesiologists, CEA carcinoembryonic antigen 
Table 5 Uni- and multivariate analyses of risk factors for overall and recurrence-free survival in patients without synchronous metastases $(n=79)$

\begin{tabular}{|c|c|c|c|}
\hline Variable & Univariate $\mathrm{P}$ Value & Multivariate $P$ Value & $\begin{array}{l}\text { Hazard Ratio } \\
\text { (95\% Confidence Interval) }\end{array}$ \\
\hline Age $\geq 60$ years & 0.39 & & \\
\hline Male sex & 0.28 & & \\
\hline $\mathrm{BMI} \geq 30 \mathrm{~kg} / \mathrm{m} 2$ & 0.79 & & \\
\hline$A S A \geq 2$ & 0.03 & 0.03 & $4(1-13)$ \\
\hline Elevated CEA & 0.17 & & \\
\hline Colon vs rectum & 0.77 & & \\
\hline Synchronous metastases & - & & \\
\hline Neoadjuvant treatment & 0.17 & & \\
\hline Emergent surgery & 0.55 & & \\
\hline Laparoscopic approach & 0.96 & & \\
\hline Multiple organ resection & 0.81 & & \\
\hline Synchronous liver resection & - & & \\
\hline $\mathrm{N}+$ status & 0.03 & 0.01 & $4(1-13)$ \\
\hline R1 margins & 0.05 & 0.02 & $3(1-8)$ \\
\hline Postoperative complications & 0.90 & & \\
\hline Grade III-IV complications & 0.82 & & \\
\hline Adjuvant chemotherapy & 0.70 & & \\
\hline
\end{tabular}

Footnotes: $B M I$ indicates body mass index, ASA American Score of Anesthesiologists, CEA carcinoembryonic antigen

may offer earlier time to adjuvant chemotherapy [27]. Further studies are required to assess the potential impact of minimally invasive surgery on the delay to adjuvant chemotherapy in the field of colorectal cancer surgery.

The impact of anastomotic leakage on long-term survival has previously been reported for malignant tumours [28-30]. Postoperative anastomotic leakage occurred in $3.7 \%$ of our patients. This result is lower compared with the results published by previous studies $([28,29] 4-20 \%)$. One explanation may include the fact that $40 \%$ of our patients had a temporary faecal diversion. The relatively low rate of anastomotic leakage in our study does not allow providing any robust conclusions on the relationship between the occurrence of POCs and survival.

Our study has several limitations. One the main limitation includes the single centre design and its retrospective nature which might decrease the ability to generalize the results. A second limitation of our analysis is the relatively short median follow-up time of 42 months. The main strength of this study is that we provide unique and comprehensive insight into the association between the most frequent complications after surgery for T4 CRC and short- and long-term outcomes.

This study provides oncologists additional data that can be used to give patient information to some extent regarding the impact of potentially postoperative complications on long-term survival after T4 CRC surgery. The development of minimally invasive approach might open the door to reduce postoperative complications and time to adjuvant chemotherapy in future studies.

\section{Conclusion}

In conclusion, this study provides persuasive evidence that POCs do not affect the oncological outcomes in patients after the resection of T4 CRC, whether the patient did or did not have synchronous liver metastases, possibly because the prognostic value of the tumour stage in T4 CCR tumours is so important that the corresponding value of POCs becomes negligible [22, 28-49].

\section{Additional file}

Additional file 1: Table S1. Additional organs resected with T4 colorectal cancer. (DOCX $17 \mathrm{~kb}$ )

\section{Abbreviations}

CRC: Colorectal cancer; CT: Computed tomography; MRI: Magnetic resonance imaging; OS: Overall survival; POC: Post-operative complications; RFS: Recurrence-free survival

Availability of data and materials

The datasets used and/or analysed during the current study are available from the corresponding author on reasonable request. 
The datasets used and/or analysed during the current study are available from the Division of General Surgery, Henri Mondor Hospital, Creteil France, on reasonable request

\section{Authors' contributions}

All authors contributed significantly to the present research and reviewed the entire manuscript. MO: Participated substantially in conception, design and execution of the study and in the analysis and interpretation of the data; also participated substantially in writing, in the drafting and editing of the manuscript. LC: Participated substantially in conception, design and execution of the study and in the analysis and interpretation of the data. AD: Participated substantially in conception, design and execution of the study and in the analysis and interpretation of the data. EL: Participated substantially in conception, design and execution of the study and in the analysis and interpretation of the data. LF: Participated substantially in conception, design and execution of the study and in the analysis and interpretation of the data. FE: Participated substantially in conception, design and execution of the study and in the analysis and interpretation of the data. TM: Participated substantially in conception, design and execution of the study and in the analysis and interpretation of the data. CS: Participated substantially in conception, design and execution of the study and in the analysis and interpretation of the data. DA: Participated substantially in conception, design and execution of the study and in the analysis and interpretation of the data; also participated substantially in the drafting and editing of the manuscript. All authors read and approved the final manuscript.

\section{Ethics approval and consent to participate}

This study was approved by the local institutional review board and ethics committee of Henri Mondor Hospital, conformed to the ethical guidelines of the 1975 Declaration of Helsinki. Written informed consent was obtained from all participants.

\section{Consent for publication}

Written informed consent was obtained from all participants to publish their data.

\section{Competing interests}

The authors declare that they have no competing interests.

\section{Publisher's Note}

Springer Nature remains neutral with regard to jurisdictional claims in published maps and institutional affiliations.

\section{Received: 17 February 2018 Accepted: 1 October 2018} Published online: 17 October 2018

\section{References}

1. Brenner H, Kloor M, Pox CP. Colorectal cancer. Lancet. Elsevier Ltd; 2014;383: 1490-1502. Available from: https://doi.org/10.1016/S0140-6736(13)61649-9

2. Gebhardt C, Meyer W, Ruckriegel S, Meier U. Multivisceral resection of advanced colorectal carcinoma. Langenbeck's Arch Surg. 1999;384:194-9.

3. Eveno C, Lefevre JH, Svrcek M, Bennis M, Chafai N, Tiret E, et al. Oncologic results after multivisceral resection of clinical T4 tumors. Surgery. Mosby, Inc.; 2014;156:669-75. Available from: http://www.sciencedirect.com/science/ article/pii/S0039606014001342

4. Bretagnol F, Dedieu a., Zappa M, Guedj N, Ferron M, Panis Y. T4 colorectal cancer: is laparoscopic resection contraindicated? Color Dis. 2011;13:138-43. Available from: http://www.ncbi.nlm.nih.gov/pubmed/20653697

5. Dimick JB, Chen SL, Taheri PA, Henderson WG, Khuri SF, Campbell DA Hospital costs associated with surgical complications: a report from the private-sector National Surgical Quality Improvement Program. J Am Coll Surg. 2004;199:531-7 Available from: http://www.ncbi.nlm.nih.gov/ pubmed/15454134

6. Vonlanthen R, Slankamenac K, Breitenstein S, Puhan MA, Muller MK Hahnloser D, et al. The impact of complications on costs of major surgical procedures: a cost analysis of 1200 patients. Ann Surg. 2011;254:907-13 Available from: http://www.ncbi.nlm.nih.gov/pubmed/21562405.

7. Khuri SF, Daley J, Henderson W, Hur K, Hossain M, Soybel D, et al. Relation of surgical volume to outcome in eight common operations: results from the VA National Surgical Quality Improvement Program. Ann Surg. 1999;230: 414-29 Available from: http://www.ncbi.nlm.nih.gov/pubmed/10493488.
8. Lagarde SM, Reitsma JB, FJW TK, ORC B, Obertop H, Zwinderman AH, et al. Predicting individual survival after potentially curative esophagectomy for adenocarcinoma of the esophagus or gastroesophageal junction. Ann Surg. 2008;248:1006-13 Available from: http://www.ncbi.nlm.nih.gov/pubmed/19092345.

9. Tokunaga M, Tanizawa Y, Bando E, Kawamura T, Terashima M. Poor survival rate in patients with postoperative intra-abdominal infectious complications following curative gastrectomy for gastric cancer. Ann Surg Oncol. 2013;20: 1575-83 Available from: http://www.ncbi.n/m.nih.gov/pubmed/23076557.

10. Doussot A, Lim C, Lahat E, Salloum C, Osseis M, Gavara CG, et al. Complications after hepatectomy for hepatocellular carcinoma independently shorten survival: a Western, single-center audit. Ann Surg Oncol. 2017:24:1569-78.

11. Heald RJ, Husband EM, Ryall RDH. The mesorectum in rectal cancer surgery???The clue to pelvic recurrence? Br J Surg. 1982;69:613-6.

12. Clavien PA, Sanabria JR, Strasberg SM. Proposed classification of complications of surgery with examples of utility in cholecystectomy. Surgery. 1992;111:51826 Available from: http://www.ncbi.nlm.nih.gov/pubmed/1598671.

13. Rahbari NN, Weitz J, Hohenberger W, Heald RJ, Moran B, Ulrich A, et al. Definition and grading of anastomotic leakage following anterior resection of the rectum: a proposal by the international study Group of Rectal Cancer. Surgery. 2010;147:339-51.

14. Dindo D, Demartines N, Clavien P-A. Classification of surgical complications: a new proposal with evaluation in a cohort of 6336 patients and results of a survey. Ann Surg. 2004;240:205-13 Available from: http://www.ncbi.nlm.nih. gov/pubmed/15273542

15. Kusters M, Austin KKS, Solomon MJ, Lee PJ, Nieuwenhuijzen GAP, Rutten HJT. Survival after pelvic exenteration for T4 rectal cancer. Br J Surg. 2015; 102:125-31 Available from: http://doi.wiley.com/10.1002/bjs.9683.

16. Leon P, lovino MG, Giudici F, Sciuto A, de Manzini N, Cuccurullo D, et al. Oncologic outcomes following laparoscopic colon cancer resection for T4 lesions: a case-control analysis of 7-years' experience. Surg Endosc. 2017; Available from: http://www.ncbi.n/m.nih.gov/pubmed/28842796.

17. Kang J, Baik SH, Lee KY, Sohn S-K. Outcomes of laparoscopic surgery in pathologic T4 colon cancers compared to those of open surgery. Int J Color Dis. 2017:32:531-8 Available from: http://link.springer.com/10.1007/ s00384-016-2720-5

18. Bellio G, Lo Cicero A, Barbieri V, Tarchi P, Casagranda B, DE Manzini N. Is T4 colon cancer still an absolute contraindication to laparoscopic surgery? Minerva Chir, Available from. 2017;72:483-90 http://www.ncbi.nlm.nih.gov/ pubmed/28425685.

19. de'Angelis N, Landi F, Vitali GC, Memeo R, Martínez-Pérez A, Solis A, et al. Multicentre propensity score-matched analysis of laparoscopic versus open surgery for T4 rectal cancer. Surg Endosc [Internet]. 2016; Available from: http://www.ncbi.nlm.nih.gov/pubmed/27826780

20. De AN, Vitali GC, Brunetti F, Wassmer C, Gagniere C, Puppa G, et al. Laparoscopic vs. Open surgery for T4 colon cancer : a propensity score analysis. Int J Colorectal Dis. 2016:1785-97 Available from: https://doi.org/10. 1007/s00384-016-2646-y.

21. Chan DKH, Tan KK. Laparoscopic surgery should be considered in T4 colon cancer. Int J Colorectal Dis. 2017:32:517-20.

22. Law WL, Choi HK, Lee YM, Ho JW. The impact of postoperative complications on long-term outcomes following curative resection for colorectal cancer. Ann Surg Oncol. 2007;14:2559-66 Available from: http:// download.springer.com/static/pdf/429/art:10.1245/s10434-007-9434-4. pdf?auth66=1405592645_1184708ad4364caae6ccff191221743f\&ext=.pdf.

23. Quirke P, Steele R, Monson J, Grieve R, Khanna S, Couture J, et al. Effect of the plane of surgery achieved on local recurrence in patients with operable rectal cancer: a prospective study using data from the MRC CR07 and $\mathrm{NCIC}$ CTG CO16 randomised clinical trial. Lancet. 2009:373:821-8.

24. Bertelsen CA, Neuenschwander AU, Jansen JE, Wilhelmsen M, KirkegaardKlitbo A, Tenma JR, et al. Disease-free survival after complete mesocolic excision compared with conventional colon cancer surgery: a retrospective, population-based study. Lancet Oncol. 2015;16:161-8.

25. Tevis SE, KohInhofer BM, Stringfield S, Foley EF, Harms BA, Heise CP, et al. Postoperative complications in patients with rectal cancer are associated with delays in chemotherapy that lead to worse disease-free and overall survival. Dis Colon Rectum. 2013;56:1339-48 Available from: http://www. ncbi.n/m.nih.gov/pubmed/24201387.

26. Babaei $M$, Balavarca $Y$, Jansen $L$, Lemmens $V$, van Erning FN, van Eycken $L$, et al. Administration of Adjuvant Chemotherapy for stage I--III Colon Cancer 
patients: a European population-based study. Int J Cancer. 2017; Available from: http://www.ncbi.nlm.nih.gov/pubmed/29159866.

27. Mirkin KA, Greenleaf EK, Hollenbeak CS, Wong J. Minimally invasive surgical approaches offer earlier time to adjuvant chemotherapy but not improved survival in resected pancreatic cancer. Surg. Endosc. Other Interv. Tech. Springer US; 2017;0:1-10. Available from: https://doi.org/10.1007/s00464-017-5937-7

28. Smith JD, Butte JM, Weiser MR, D'Angelica MI, Paty PB, Temple LK, et al. Anastomotic leak following low anterior resection in stage IV rectal cancer is associated with poor survival. Ann Surg Oncol. 2013;20:2641-6 Available from: http://www.ncbi.nlm.nih.gov/pubmed/23385965.

29. Hain E, Maggiori L, Manceau G, Mongin C, Prost à la Denise J, Panis Y. Oncological impact of anastomotic leakage after laparoscopic mesorectal excision. Br J Surg. 2016; Available from: http://doi.wiley.com/10.1002/bjs.10332.

30. Kulu Y, Tarantio I, Warschkow R, Kny S, Schneider M, Schmied BM, et al. Anastomotic leakage is associated with impaired overall and disease-free survival after curative rectal cancer resection: a propensity score analysis. Ann Surg Oncol. 2015;22:2059-67 Available from: http:/www.ncbi.nlm.nih. gov/pubmed/25348782.

31. Law WL, Chu KW. Anterior resection for rectal Cancer with Mesorectal excision. Ann Surg. 2004;240:260-8 Available from: http://www.scopus.com/ inward/record.url?eid=2-s2.0-3242685186\&partnerlD=tZOtx3y1.

32. Eriksen MT, Wibe A, Norstein J, Haffner J, Wiig JN. Anastomotic leakage following routine mesorectal excision for rectal cancer in a national cohort of patients. Color Dis. 2005;7:51-7 Available from: http://onlinelibrary.wiley. com/doi/10.1111/j.1463-1318.2004.00700.x/abstract.

33. Walker KG, Bell SW, Rickard MJ, Mehanna D, Dent OF, Chapuis PH, et al. Anastomotic leakage is predictive of diminished survival after potentially curative resection for colorectal cancer. Ann Surg. 2004;240:255-9 Available from: http://www.ncbi.nlm.nih.gov/pmc/articles/PMC1356401/pdf/ 20040800s00010p255.pdf.

34. Eberhardt JM, Kiran RP, Lavery IC. The impact of anastomotic leak and intraabdominal abscess on cancer-related outcomes after resection for colorectal cancer: a case control study. Dis Colon Rectum. 2009;52:380-6.

35. Branagan G, Finnis D, Wessex Colorectal Cancer Audit Working Group. Prognosis after anastomotic leakage in colorectal surgery. Dis Colon Rectum. 2005;48: 1021-6 Available from: http://www.ncbi.nlm.nih.gov/pubmed/15789125.

36. McArdle CS, McMillan DC, Hole DJ. Impact of anastomotic leakage on longterm survival of patients undergoing curative resection for colorectal cancer. Br J Surg. 2005;92:1150-4.

37. Ptok H, Marusch F, Meyer F, Schubert D, Gastinger I, Lippert H. Impact of anastomotic leakage on oncological outcome after rectal cancer resection. Br J Surg. 2007;94:1548-54.

38. Lee W-S, Yun SH, Roh Y-N, Yun H-R, Lee WY, Cho YB, et al. Risk factors and clinical outcome for anastomotic leakage after total mesorectal excision for rectal cancer. World J Surg 2008;32:1124-9. Available from: http://www.ncbi. nlm.nih.gov/pubmed/18259805

39. Den Dulk M, Marijnen CAM, Collette L, Putter H, Påahlman L, Folkesson J, et al. Multicentre analysis of oncological and survival outcomes following anastomotic leakage after rectal cancer surgery. Br J Surg. 2009;96:1066-75.

40. Bertelsen CA, Andreasen AH, Jørgensen T, Harling H. Anastomotic leakage after curative anterior resection for rectal cancer: short and long-term outcome. Color Dis. 2010;12:e76-81.

41. Jörgren F, Johansson R, Damber L, Lindmark G. Anastomotic leakage after surgery for rectal cancer: a risk factor for local recurrence, distant metastasis and reduced cancer-specific survival? Color Dis. 2011;13:272-83.

42. Mirnezami A, Mirnezami R, Chandrakumaran K, Sasapu K, Sagar P, Finan P. Increased local recurrence and reduced survival from colorectal cancer following anastomotic leak systematic review and meta-analysis. Ann Surg. 2011:253:890-9

43. Gooiker GA, JWT D, Bastiaannet E, van der Geest LGM, Merkus JWS, van de Velde $\mathrm{CJH}$, et al. Risk factors for excess mortality in the first year after curative surgery for colorectal Cancer. Ann Surg Oncol. 2012;19:2428-34 Available from: http://www.pubmedcentral.nih.gov/articlerender.fcgi?artid= 3404283\&tool=pmcentrez\&rendertype $=$ abstract

44. Henneman D, Ten Berge MG, Snijders HS, van Leersum NJ, Fiocco M, Wiggers $\mathrm{T}$, et al. Safety of elective colorectal cancer surgery: non-surgical complications and colectomies are targets for quality improvement. J Surg Oncol. 2014;109:567-73 Available from: http://www.ncbi.nlm.nih.gov/ pubmed/24338627.

45. Odermatt M, Miskovic D, Flashman K, Khan J, Senapati A, O'Leary D, et al. Major postoperative complications following elective resection for colorectal cancer decrease long-term survival but not the time to recurrence. Color Dis. 2015;17:141-9 Available from: http://www.ncbi.nlm. nih.gov/pubmed/25156234.

46. Ebinger SM, Warschkow R, Tarantino I, Schmied BM, Marti L. Anastomotic leakage after curative rectal cancer resection has no impact on long-term survival: a propensity score analysis. Int J Color Dis. 2015;30:1667-75.

47. Breugom AJ, van Dongen DT, Bastiaannet E, Dekker FW, van der Geest LG, Liefers GJ, et al. Association between the Most frequent complications after surgery for stage I-III Colon Cancer and short-term survival, long-term survival, and recurrences. Ann Surg Oncol. 2016;23:2858-65.

48. Jamnagerwalla M, Tay R, Steel M, Keck J, Jones I, Faragher I, et al. Impact of surgical complications following resection of locally advanced rectal adenocarcinoma on adjuvant chemotherapy delivery and survival outcomes. Dis Colon Rectu. 2016;59:916-24 Available from: http://journals. Iww.com/dcriournal/pages/default.aspx\%5Cnhttp://ovidsp.ovid.com/ ovidweb.cgi?T=JS\&PAGE=reference\&D=emed 18b\&NEWS=N\&AN=612302827.

49. Nordholm-Carstensen A, Rolff HC, Krarup P-M. Differential impact of anastomotic leak in patients with stage IV colonic or rectal Cancer: a Nationwide cohort study. Dis Colon Rectum. 2017;60:497-507 Available from: http://www.ncbi.nlm.nih.gov/pubmed/28383449.

\section{Ready to submit your research? Choose BMC and benefit from:}

- fast, convenient online submission

- thorough peer review by experienced researchers in your field

- rapid publication on acceptance

- support for research data, including large and complex data types

- gold Open Access which fosters wider collaboration and increased citations

- maximum visibility for your research: over $100 \mathrm{M}$ website views per year

At BMC, research is always in progress.

Learn more biomedcentral.com/submissions 